\title{
Self-Awareness, Probability of Improvement, and the Self-Serving Bias
}

\author{
Thomas Shelley Duval \\ University of Southern California
}

\author{
Paul J. Silvia \\ University of Kansas
}

\begin{abstract}
Evidence for the self-serving bias (attributing success internally and failure externally) is inconsistent. Although internal success attributions are consistently found, researchers find both internal and external attributions for failure. The authors explain these disparate effects by considering the intersection of 2 systems, a system comparing self against standards and a causal attribution system. It was predicted that success and failure attributions are moderated by self-awareness and by the ability to improve. When self-focus is high (a) success is attributed internally, (b) failure is attributed internally when people can improve, (c) failure is attributed externally when people cannot improve, and (d) these attributions affect state self-esteem. Implications for the self-serving bias are discussed.
\end{abstract}

The self-serving attributional bias-attributing success internally and failure externally - appears for many psychologists to have achieved the status of an empirical fact (Brown \& Rogers, 1991). Researchers indeed find a consistent tendency for individuals to attribute success to self (e.g., Miller \& Ross, 1975). Yet the literature on failure attributions shows a lot of variability. Many experiments find external attributions for failure (e.g., Snyder, Stephan, \& Rosenfield, 1976, 1978). Many other studies, however, find internal attributions for failure (e.g., Ames, 1975; Ross, Bierbrauer, \& Polly, 1974; Weary et al., 1982). In fact, Zuckerman's (1979) qualitative review reveals broad diversity in effects. Among 13 studies on attributions for failed interpersonal influence, for example, 5 found a self-serving pattern, 4 found a non-self-serving pattern, and 4 found no effects. A recent quantitative review found that the distribution of effect sizes ranged across positive and negative values (Campbell \& Sedikides, 1999, p. 34); self-serving and non-self-serving effects were observed frequently.

The diversity of effects for failure attributions seems reasonable when we consider the costs of a dominant tendency toward defensiveness. As Nisbett and Ross (1980) argued

The costs of willy-nilly distortions in perception are simply too high to make them a cure-all for the disappointed or threatened perceiver. In general, misperceptions make us less able to remedy the situations

Thomas Shelley Duval, Department of Psychology, University of Southern California; Paul J. Silvia, Department of Psychology, University of Kansas.

Both authors contributed equally to this article. We thank Laurie O'Brien for her statistical advice. These experiments were presented at the meeting of the Midwestern Psychological Association in Chicago, May 2001. Preparation of this article was supported by National Science Foundation Grant CSM 9726575.

Correspondence concerning this article should be addressed to Thomas Shelley Duval, Department of Psychology, SGM 501, University of Southern California, Los Angeles, California 90089-1061, or to Paul J. Silvia, who is now at Psychology Institute II, University of Hamburg, Von-MellePark 5, D-20146 Hamburg, Germany. E-mail: duval@usc.edu or paulsilvia@hotmail.com that threaten us or give us pain than do accurate perceptions. In a sense, they poorly serve the goals of maximizing pleasure and minimizing pain in the long term. (p. 234)

At a more general level, people have many motives and goals simultaneously (Heider, 1958; Lewin, 1935). The presence of contradictory effects suggests that unidentified moderators and additional motivations are operating. Our goal is to develop a model of self-serving attributions based on the interplay of two motivational systems, which we discuss in more detail below.

\section{Self-Enhancement and Self-Assessment}

Self-enhancement motivation engenders a preference for cognitions and interpretations that foster a positive self-concept. This general motive has broad psychological consequences (Dunning, 1999; Taylor \& Brown, 1988). Research on self-understanding (Sedikides, 1993), for instance, shows that people seek selfknowledge in ways designed to yield flattering results. After self-reflecting, people preferred to ask highly diagnostic questions of themselves when the trait was highly self-relevant and positively valenced. When the trait was highly self-relevant and negatively valenced, people selected less diagnostic questions. People also generated questions judged to be more diagnostic when the trait was central to self and positive, as opposed to central and negative. Finally, people consistently affirmed possessing positively valenced traits and denied having negative traits.

Yet self-enhancement is not the only motive associated with the self-concept. People also want accurate information about the extent of their abilities and the correctness of their opinions (Festinger, 1954; Trope, 1986). Self-assessment motivation promotes seeking and preferring information that provides accurate knowledge about the self (Sedikides \& Strube, 1997). Such knowledge is not necessarily flattering or unflattering to one's self-image. The operation of self-assessment motivation is seen when people seek accurate feedback about their limitations and liabilities, even though this information hinders self-enhancement (Trope \& Neter, 1994; Trope \& Pomerantz, 1998).

In sum, people are motivated to self-enhance and to self-assess, and these motives may occasionally conflict. Initial research on 
self-enhancement and self-assessment tried to show that one or the other dominated activity. Sedikides (1993), for example, attempted to create conditions in which the positions' predictions could be pitted against one another; he concluded that self-assessment was subordinate to self-enhancement. More recently, Sedikides and Strube (1997) argued that accurate self-assessment occurs, but always in the service of long-term self-enhancement. Other researchers have argued that neither motive is dominant (e.g., Dunning, 1995). In this view, the task is to explore when one or the other motive prevails, not to assume that one motive is inherently stronger. We use this outlook in our model of self-serving attributions, which we describe in detail below.

\section{A Dual Systems Model of Self-Serving Attributions}

We view self-serving attributions as the result of the interaction of two systems, a system comparing self against standards of correctness (Duval \& Wicklund, 1972) and a causal attribution system (Heider, 1944, 1958). This first system compares the present state of self against salient standards of correctness whenever attention is focused internally on the self (Duval \& Silvia, 2001). The self-to-standard comparison system (SSCS) is a goaldirected system. Its preferred state is maximal similarity between self and standards. If a comparison finds self to be discrepant from standards, then negative affect occurs (Ickes, Wicklund, \& Ferris, 1973; Sedikides, 1992). But if a comparison finds self to be congruent with standards, then positive affect occurs (Ickes et al., 1973; McDonald, 1980). The person's hedonic inclination-avoiding negative affect and seeking positive affect-leads to efforts at self-enhancement, viewed here as meeting one's personal standards describing how self ought to be. Support for these predictions is reviewed in detail elsewhere (Duval \& Silvia, 2001; Silvia \& Duval, 2001a).

The second system is the causal attribution system. People spontaneously strive to understand the world by making attributions for events (Duval \& Duval, 1983; Heider, 1944; Wong \& Weiner, 1981). Attributional processes are influenced by motivational principles. Rather than randomly attributing events to any possible cause, people instead prefer to connect effect events to a plausible cause. An accurate understanding of one's abilities requires an accurate understanding of what the self can and cannot bring about or influence in the environment. The attribution system, then, can also be understood as a motivational system, one that reflects the motive to seek accurate information about the causal structure of the world (Heider, 1958).

It appears, then, that the attribution system and the SSCS have different goals. One prefers congruity between self and standards, whereas the other prefers an accurate causal understanding. The goals of the two systems can thus relate in three ways: They can be unrelated, in conflict, or in harmony. The systems' goals are unrelated when an event occurs whose cause has no implications for self-standard congruity, such as why a neighbor's child fell ill. Provided that the self did not somehow provoke the illness, any attribution for the event does not influence the degree of incongruity between the self and standards.

For our purposes, situations in which the goals coincide or conflict are more interesting. The systems' goals coincide when self is a plausible cause for success-attributing success to self moves self toward standards and also links an event with a plau- sible cause. Both goal states are thus facilitated by an internal attribution to self; this should bolster such attributions, as shown by the empirical evidence (Miller \& Ross, 1975; Zuckerman, 1979). But the systems' goals conflict when self is a plausible cause for failure. Attributing failure to self would result in accurate causal understanding, but it would simultaneously increase selfstandard discrepancy. Conversely, an external attribution would preserve self-standard congruity, but it would require the attribution system to link failure with an implausible cause. How is this conflict resolved?

\section{Probability of Improvement as a Moderator}

The person's perceived probability of improving his or her failure should moderate failure attributions. Duval and Duval (1983, 1987), for example, argued that perceiving a high probability of improvement will lead to an internal failure attribution. Granted, locating causality for failure in self should increase incongruity between self and standards and, thus, negative affect. Yet perceiving improvement as likely should lead to the expectation that self-standard congruency will be quickly restored. Any short-term costs to self-esteem are thus offset by long-term benefits in accurate self-assessment. But when future improvement seems unlikely, attribution of failure to self would produce an irreducible discrepancy and high negative affect. In this situation, the benefits of accurate causal knowledge seem outweighed by the long-term drop in self-esteem, given that one's personal failing is seen as permanent (Duval \& Duval, 1987).

Research manipulating the perceived malleability of traits is compatible with this approach. Dunning (1995) led participants to believe that they had either succeeded or failed on a task measuring an intellectual ability, which was either important or inconsequential. The ability was said to be either modifiable or unmodifiable. A modifiable trait was described as "one of the most changeable, least stable, intellectual abilities around" (p. 1302) on which people could either "increase dramatically by practicing" or "let it drop by ignoring it" (p. 1302). An unmodifiable trait was described as "one of the most stable, least changeable, intellectual abilities - either you have it or you don't" (p. 1302). These manipulations could be construed as inducing high and low probabilities of improvement. The dependent measure was whether people preferred taking a test that did or did not provide feedback. People who felt deficient in an important and modifiable ability preferred to take additional tests offering performance feedback rather than tests not offering feedback. In contrast, people who felt deficient in an important but unmodifiable ability preferred tests not offering feedback. Although attributions were not measured, these findings are compatible with our general predictions. People who believed their deficiency was malleable sought accurate information; those who believed their deficiency was stable sought situations affording self-enhancement.

People also hold different theories about the malleability of traits (Dweck, Chiu, \& Hong, 1995), which seem to influence failure attributions in line with our predictions. Dweck and her colleagues (Hong, Chiu, Dweck, Lin, \& Wan, 1999) first categorized people according to implicit theories of trait malleability. One group consisted of persons who believed personal attributes to be relatively fixed (entity theorists); the second group believed that attributes are relatively malleable (incremental theorists). The at- 
tributional consequences of this typology were explored by giving failure feedback to the different theorists and then measuring attributions to ability and effort. Incremental theorists attributed more causality for failure to effort than did the entity theorists. Contrary to predictions, the groups did not differ in their attributions to ability. Yet the results for attribution to effort are consistent with our approach if one assumes that incremental theorists believe that failure can be quickly improved, whereas entity theorists believe that failure cannot be improved.

\section{The Role of Self-Awareness}

Our model assumes that a second variable, level of selfawareness, also moderates attributions. The system comparing self against standards only operates inasmuch as attention is directed inward on the self (Duval \& Wicklund, 1972). When selfawareness is low, the relationship between self and any given standard is indistinct and obscure to the person. This simply reflects the "spotlight" function of attention (Treisman \& Gelade, 1980): It is difficult to assess similarities and differences among elements unless they receive attentional processing. If the person is unaware of how self and standard match up, then any discrepancies that might exist will not have any affective and motivational consequences. Yet when self-awareness is heightened, the person can discriminate similarities and differences between the self's current state and the standard. This enables the person to feel positively about congruent relationships and negatively about incongruent relationships. Indeed, decades of research (Carver \& Scheier, 1998; Silvia \& Duval, 2001a) show that the degree of self-focused attention directly affects the degree of self-to-standard comparison (e.g., Scheier \& Carver, 1983). Increasing self-focus beyond baseline levels intensifies the affective and motivational consequences of the comparison process (Silvia \& Gendolla, 2001). Likewise, decreased self-focus, such as in deindividuation (Diener, 1979), attenuates the effects of self-standard comparison.

If self-awareness is low, then the SSCS is essentially inert. As a result, it cannot interact with the attribution system; the two systems' goals thus cannot conflict. An absence of conflict means that there is nothing for improvement beliefs to reconcile, so perceived probability of improving failure should not have any effects on attribution when self-awareness is low. But when selfawareness is high, the comparison system is activated. People become keenly aware of self-standard discrepancies, and the potential for conflict with the attribution system arises. Probability of improvement is thus capable of moderating failure attributions because it can reconcile the competing demands of accurate selfassessment and positive self-enhancement.

\section{Predictions}

To summarize, when self-awareness is high and self is a plausible cause for success and failure, we expect that (a) attribution of success to self will be amplified because the two systems' motives coincide, (b) failure will be attributed to self when people expect a high probability of future improvement, (c) failure will be attributed externally when people do not expect future improvement, and (d) attributions will influence state self-esteem. When self-awareness is low, improvement likelihood should not affect attribution or self-esteem; self-enhancement concerns are reduced when people are not comparing the self against personal standards.

\section{Experiment 1}

\section{Method}

\section{Overview}

Participants worked on a self-relevant task when self-awareness was either high or low. To create a discrepancy between self and standards, we told all participants that they performed below the study's standard. They were then led to perceive either a high $(98.3 \%)$ or low $(2.5 \%)$ probability of improving their poor performance in the future. Attributions for failure were then measured.

\section{Participants}

Participants were 40 male introductory psychology students who volunteered to participate for extra course credit. Each was randomly assigned to condition in a 2 (camera/no camera) $\times 2$ (high/low improvement likelihood) factorial design.

\section{Procedure}

Participants arrived individually and were seated at a table in front of a TV monitor. The experimenter explained that the study was part of a research program sponsored by the National Institute for the Study of Intellectual Abilities. The study's purpose was to assess whether the participant was deficient in the ability to make quantitative judgments in three dimensions. If the person was deficient, then the assessment procedures would indicate the degree of deficiency and evaluate the probability that the person could improve in the future. To increase the task's selfrelevance, the experimenter indicated that this judgmental capacity could affect performance on several important intellectual tasks and was highly correlated with future career success.

Self-awareness manipulation. In the high self-awareness conditions, a tripod-mounted video camera was placed $3 \mathrm{ft}$ away from the participant and focused in a tight head shot (Davis \& Brock, 1975; Duval, 1976; Duval, Duval, \& Mulilis, 1992). Questionnaire responses and experimental feedback could not be seen on the TV monitor, thus minimizing impression management interpretations (Dana, Lalwani, \& Duval, 1997; Duval \& Lalwani, 1999). Participants were told that the National Institute requested the videotaping of a random sample of sessions, presumably to ensure standardization of testing conditions, and that the present session had been randomly selected for videotaping. The video of the present session would ostensibly be briefly viewed by the experimenters and then erased. In the low self-awareness conditions, the video camera faced the wall and all wires were disconnected from electrical outlets. Participants were given the same information but were told they had not been randomly chosen for videotaping.

After the self-awareness manipulation, the participant was told that he would be assessed with regard to (a) whether he was deficient in the domain of quantitative judgments in three dimensions, (b) the degree of deficiency, and (c) the probability that he could improve through practice. Assessment of these dimensions was presumably achieved by computer analyses of the number of correct and incorrect responses and the overall pattern of responses on the test. Analysis of the number of correct and incorrect responses would indicate whether he currently met the standard. If he did not meet the standard, further analyses of the pattern of responses would yield a highly accurate prediction of the likelihood of eliminating the deficiency.

The experimenter then said that the capacity to make quantitative judgments in three dimensions involved the ability to understand the solution to 
problems with only some of the relevant facts available. People were often unaware of a deficiency because its only noticeable effect was a tendency to make errors on problems requiring quantitative judgments, an effect usually attributed to lapses in attention. This information was conveyed to make the forthcoming failure feedback more plausible.

The "diagnostic test" involved deciding which of five two-dimensional figures, when folded to make a three-dimensional figure, would match the criterion three-dimensional figure shown in the test item. The experimenter gave the participant two sample test items, turned on the videotape of the test, and left the room. A total of 45 problems were presented on a TV monitor in sets of 3 problems. After $45 \mathrm{~s}$ of exposure to each set, the program continued to the next set; this procedure continued until all 45 problems had been presented.

The experimenter then reentered the room and took the participant's answer sheet to be analyzed. The experimenter actually went to a separate room and picked up a computer printout that another member of the research team had randomly designated for that participant. After $5 \mathrm{~min}$, he returned to the participant's cubicle and opened the feedback sheet. The experimenter had been unaware of the participant's probability of improvement up to this point.

Failure feedback and probability of improvement manipulation. After opening the printout, the experimenter told all participants that analyses indicated a deficiency in their ability to make quantitative judgments. Pointing to a statement at the bottom of the printout, he explained that the participant "was deficient from the standard level of ability by $10 \%$." In the high probability of improvement condition, he pointed out that the computer analyses indicated a $98.3 \%$ probability of substantially reducing the deficiency through practice on related problems. In the low probability of improvement condition, the computer analyses indicated a $2.5 \%$ probability of future improvement. The experimenter then left the room to ensure that his presence did not increase self-focus (Carver \& Scheier, 1978; Scheier, Fenigstein, \& Buss, 1974). Participants completed a questionnaire containing manipulation checks, dependent measures of causal attribution, and several filler items.

\section{Dependent Measures}

Causal attributions for failure were measured with two items, "To what extent was your performance on the test caused by factors associated with yourself?" and "To what extent was your performance on the test caused by factors associated with the external environment?" Each question was answered on a 7-point scale anchored by not at all and very much.

To check the probability of improvement manipulation, we asked participants, "To what extent can you improve your performance on the task in the future?" answered on a similar 7-point scale.

\section{Results and Discussion}

\section{Manipulation Check}

A 2 (camera/no camera) $\times 2$ (high/low probability of improvement) analysis of variance (ANOVA) conducted on the improvement manipulation check yielded a sole main effect for probability of improvement, $F(1,36)=91.07, p<.001$. As expected, people in the high probability of improvement condition expressed a greater likelihood of improving in the future relative to people in the low probability of improvement condition.

\section{Attributions for Failure}

We created a single attribution score for each person by subtracting external attributions from internal attributions. The pattern is presented in Figure 1. An ANOVA revealed a significant main effect for probability of improvement, $F(1,36)=10.16, p<.01$,

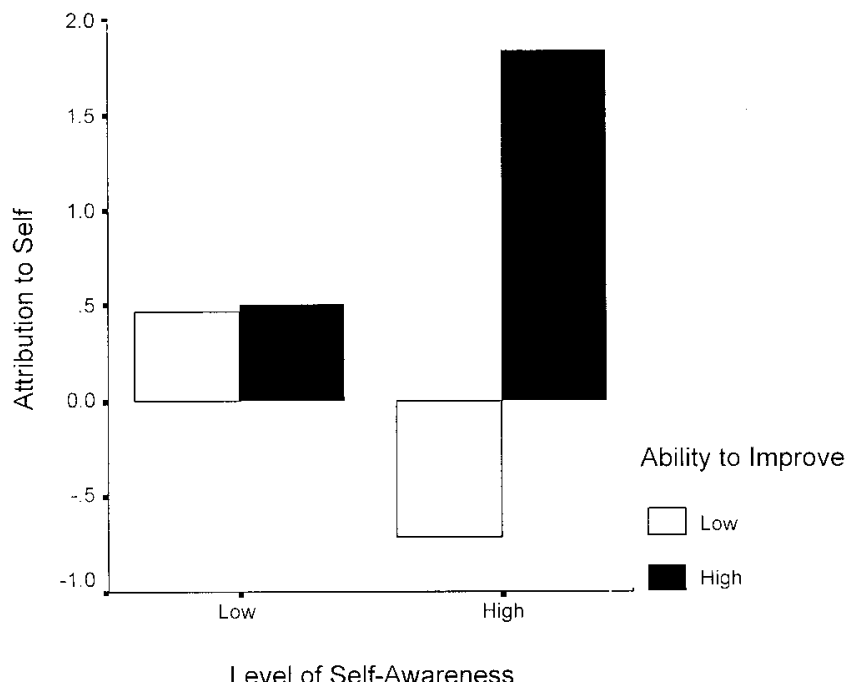

Figure 1. Failure attribution to self as a function of self-awareness and improvement likelihood: Study 1.

and a significant interaction, $F(1,36)=9.54, p<.01$. When self-awareness was high, persons expecting improvement attributed more causality for failure to self than did persons not expecting improvement, $t(36)=4.44, p<.001$. When probability of improvement was high, highly self-aware persons attributed more causality to self than did mildly self-aware persons, $t(36)=2.32$, $p<.01$. But when probability of improvement was low, highly self-aware persons attributed less causality to self than did mildly self-aware persons, $t(36)=2.05, p<.05$. Probability of improvement had no effect in the no-camera conditions; $t<1$.

Experiment 1 thus supports our predictions; self-awareness and probability of improvement interactively determined failure attributions. When self-awareness was high, people who expected improvement attributed failure internally, and people who did not expect improvement attributed failure externally. Probability of improvement had no impact when self-awareness was low, presumably because self-evaluative concerns are minimal when people are not comparing self against standards.

\section{Experiment 2}

In Experiment 2 we addressed two issues. First, we wanted to replicate our findings using different measures of attribution. In Experiment 2, participants first made attributions for failure using the four dimensions of ability, effort, task difficulty, and luck. This fourfold typology allows a more differentiated look at internal (ability and effort) and external (task difficulty and luck) attributions. We then measured attributions with the two-item internalexternal index used in Experiment 1. Second, we wanted to explore the consequences of failure attributions for state self-esteem. Perceiving the self as the cause of failure should decrease state self-esteem. McFarland and Ross (1982) demonstrated this effect by directly manipulating failure attributions; they simply told people that either internal or external factors caused their failure. As expected, persons attributing failure internally expressed lower state self-esteem than did persons attributing failure externally. These effects should hold when failure attributions occur in a more 
spontaneous fashion. Thus, our model predicts that highly selffocused people expecting improvement will attribute failure to self and, as a result, experience lower state self-esteem. Highly selffocused persons not expecting improvement will attribute failure externally and, as a result, experience no change in state selfesteem. This effect would be inconsistent with explanations for the self-serving bias based on invariant motives to enhance or protect self-esteem (e.g., Snyder et al., 1978).

\section{Method}

\section{Participants}

Participants were 40 male introductory psychology students who volunteered to participate for extra course credit. Each was randomly assigned to condition in a 2 (camera/no camera) $\times 2$ (high/low probability of improvement) factorial design.

\section{Procedure}

The procedure was identical to Experiment 1. Participants worked on a task, received failure feedback, and expected either a high or low probability of improving.

\section{Dependent Measures}

Participants first completed a state self-esteem scale (McFarland \& Ross, 1982) consisting of 16 adjectives (e.g., pride, worthless, shame). We used this scale because it was specifically designed to measure the effects of internal and external attributions on state self-esteem; McFarland and Ross reported validation evidence. It is thus more appropriate for our purposes than more general self-esteem measures (e.g., Heatherton \& Polivy, 1991).

Two separate causal attribution measures were obtained. The first measure consisted of four items: "To what extent was your performance on the test caused by your ability?" "To what extent was your performance on the test caused by your effort?" "To what extent was your performance on the test caused by the difficulty of the test?" and "To what extent was your performance on the test caused by luck?" The second attribution measure, as in Experiment 1, consisted of two items: "To what extent was your performance on the test caused by factors associated with yourself?" and "To what extent was your performance on the test caused by factors associated with the external environment?" Each question was answered on a 7-point scale anchored by not at all and very much.
As a check on the probability of improvement manipulation, participants were asked, "To what extent can you improve your performance on the task in the future?" answered on a similar 7-point scale.

\section{Results}

\section{Manipulation Check}

A 2 (camera/no camera) $\times 2$ (high/low probability of improvement) ANOVA conducted on the manipulation check revealed a sole main effect for probability of improvement, $F(1,36)=48.5$, $p<.001$. As expected, people in the high probability of improvement conditions perceived a greater likelihood of improvement than did people in the low probability of improvement conditions.

\section{Attributing Failure to Ability, Effort, Task Difficulty, and Luck}

Ability. Failure attributions to ability are presented in Table 1. A $2 \times 2$ ANOVA revealed a significant main effect for probability of improvement, $F(1,36)=10.56, p<.01$, qualified by a significant interaction, $F(1,36)=12.5, p<.01$. When selfawareness was high, persons expecting improvement attributed more causality to ability than did persons not expecting improvement, $t(36)=4.85, p<.01$. When probability of improvement was high, highly self-aware persons made more attribution to ability than did mildly self-aware persons, $t(36)=2.97, p<.01$. But when probability of improvement was low, highly self-aware persons attributed less causality to ability than did mildly selfaware persons, $t(36)=2.08, p<.05$. Probability of improvement had no effect in the no camera conditions, $t<1$.

Effort. Failure attributions to effort are presented in Table 1. A $2 \times 2$ ANOVA revealed a significant main effect for probability of improvement, $F(1,36)=7.24, p<.05$, qualified by a significant interaction, $F(1,36)=12.76, p<.01$. When self-awareness was high, persons expecting improvement attributed more causality to effort than did persons not expecting improvement, $t(36)=4.43$, $p<.01$. When probability of improvement was high, highly self-aware persons attributed more to effort than did mildly selfaware persons, $t(36)=2.9, p<.01$. But when probability of improvement was low, highly self-aware persons attributed less causality to effort than did mildly self-aware persons, $t(36)=2.15$,

Table 1

Attributions to Ability, Effort, Task Difficulty, and Luck: Experiment 2

\begin{tabular}{|c|c|c|c|c|c|c|c|c|}
\hline \multirow[b]{3}{*}{ Variable } & \multicolumn{8}{|c|}{ Probability of improvement } \\
\hline & \multicolumn{4}{|c|}{ High } & \multicolumn{4}{|c|}{ Low } \\
\hline & Ability & Effort & Task & Luck & Ability & Effort & Task & Luck \\
\hline \multicolumn{9}{|l|}{ Camera } \\
\hline$M$ & 5.82 & 5.43 & 1.64 & 2.36 & 1.55 & 1.44 & 6.24 & 4.84 \\
\hline$S D$ & 1.86 & 1.95 & 2.12 & 1.85 & 2.00 & 1.89 & 1.95 & 1.64 \\
\hline \multicolumn{9}{|l|}{ No camera } \\
\hline$M$ & 3.20 & 2.82 & 4.05 & 4.32 & 3.38 & 3.38 & 3.38 & 3.46 \\
\hline$S D$ & 1.97 & 1.85 & 2.01 & 1.69 & 1.70 & 1.96 & 2.07 & 1.77 \\
\hline
\end{tabular}

Note. $n=10$ per cell. As means increase, attribution to the given dimension increases. Scale values range from 1 to 7 . 
$p<.05$. Probability of improvement had no effect in the no camera conditions, $t<1$.

Task difficulty. Attributions to task difficulty are shown in Table 1 . A $2 \times 2$ ANOVA revealed a significant probability of improvement main effect, $F(1,36)=10.72, p<.01$, qualified by a significant interaction, $F(1,36)=13.10, p<.01$. When selfawareness was high, persons expecting improvement attributed less causality to task difficulty than did persons not expecting improvement, $t(36)=4.76, p<.01$. When probability of improvement was high, highly self-aware persons attributed less to task difficulty than did mildly self-aware persons, $t(36)=2.51, p<$ .05 . But when probability of improvement was low, highly selfaware persons attributed more causality to task difficulty than did mildly self-aware persons, $t(36)=2.52, p<.05$. Probability of improvement had no effect in the no camera conditions, $t<1$.

Luck. Attributions to luck are displayed in Table 1. A $2 \times 2$ ANOVA revealed a significant interaction, $F(1,36)=8.33, p<$ .01 . When self-awareness was high, persons expecting improvement attributed less causality to luck than did persons not expecting improvement, $t(36)=3.02, p<.01$. When probability of improvement was high, highly self-aware persons attributed less to luck than did mildly self-aware persons, $t(36)=2.39, p<.05$. When probability of improvement was low, no significant difference was found between the high and low self-awareness conditions, $t(36)=1.68, p>.10$. Probability of improvement had no effects in the no camera conditions, $t<1$.

\section{Attributing Failure to Internal and External Factors}

We created a single attribution score for each person by subtracting external attributions from internal attributions. The pattern is presented in Figure 2. An ANOVA revealed a significant probability of improvement main effect, $F(1,36)=9.28, p<.01$, qualified by a significant interaction, $F(1,36)=11.16, p<.01$. When self-awareness was high, persons expecting improvement attributed more causality for failure to self than did persons not expecting improvement, $t(36)=4.52, p<.01$. When probability

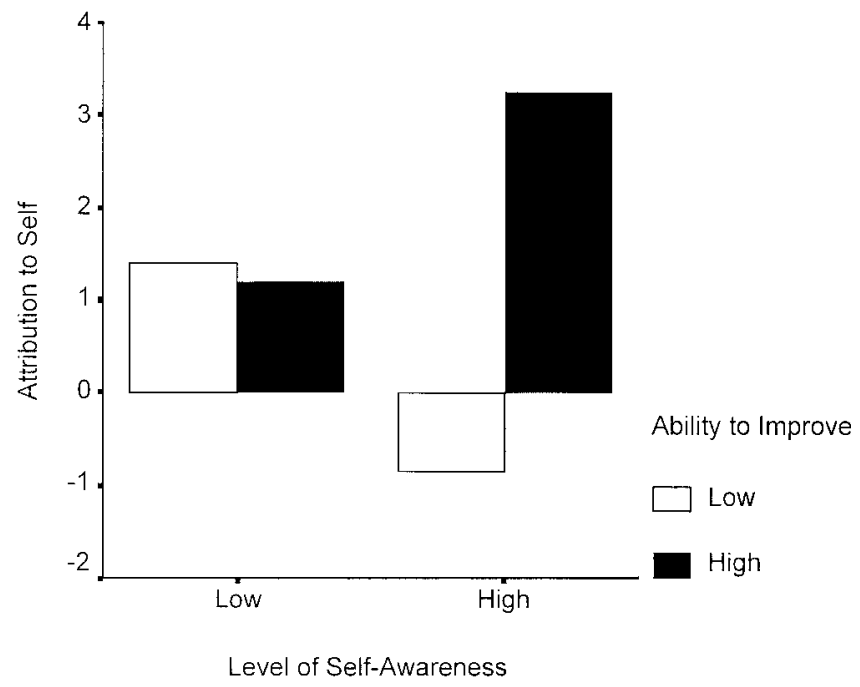

Figure 2. Failure attribution to self as a function of self-awareness and improvement likelihood: Study 2. of improvement was high, highly self-aware persons attributed more causality to self than did mildly self-aware persons, $t(36)=2.25, p<.05$. But when probability of improvement was low, highly self-aware persons attributed less causality to self than did mildly self-aware persons, $t(36)=2.08, p<.05$. Probability of improvement had no effect in the no camera conditions, $t<1$.

\section{State Self-Esteem}

A $2 \times 2$ ANOVA conducted on the state self-esteem data found a significant main effect for probability of improvement, $F(1$, $36)=6.37, p<.01$, and a significant interaction, $F(1,36)=$ $11.41, p<.01$. The pattern is shown in Figure 3. When selfawareness was high, persons expecting improvement reported lower state self-esteem than did persons not expecting improvement, $t(36)=4.44, p<.01$. When probability of improvement was high, highly self-aware persons reported lower self-esteem than did mildly self-aware persons, $t(36)=3.06, p<.01$. No other differences were found, $t<1$.

\section{Mediational Analyses}

We expected that the effects of probability of improvement on self-esteem were mediated by attributions for failure. To assess mediation indirectly, we conducted a series of regression analyses on the responses of persons in the high self-awareness conditions (Baron \& Kenny, 1986). Attribution was quantified by a single attribution score [(ability + effort) - (task difficulty + luck)] derived from the fourfold typology. Probability of improvement significantly predicted both self-esteem $(\beta=.632, p<.003)$ and failure attributions $(\beta=-.917, p<.001)$. When probability of improvement and attributions for failure were considered simultaneously, attributions significantly predicted self-esteem $(\beta=$ $-1.518, p<.001$ ), and probability of improvement had a significant direct effect $(\beta=-.761, p<.02)$. We will defer interpreting this latter effect until Experiment 3, given our small sample size $(n=20)$ for this type of analysis (Cohen \& Cohen, 1983, p. 59; Pedhazur, 1982).

To assess mediation directly, we conducted Baron and Kenny's (1986) modified version of the Sobel (1982) test (see Kenny, Kashy, \& Bolger, 1998, p. 260), which provides a direct estimate of whether a variable mediates between an independent and a dependent variable. This test also revealed that the effect of improvement likelihood on self-esteem was significantly mediated by failure attributions $(Z=4.52, p<.001)$.

\section{Discussion}

Experiment 2 replicated the attribution data obtained in the first study: Highly self-focused people attributed failure internally when probability of improvement was high and externally when probability of improvement was low. Multiple attribution measures showed this pattern, which increases our confidence in the effect's reliability. Indeed, the effect appeared on both internal (ability and effort) and external measures. This shows that people were simultaneously seeing the self as less culpable for failure and external factors as more culpable. Moving beyond replication, Experiment 2 showed that internal and external attributions have corresponding effects on self-esteem. The fact that people attribute 


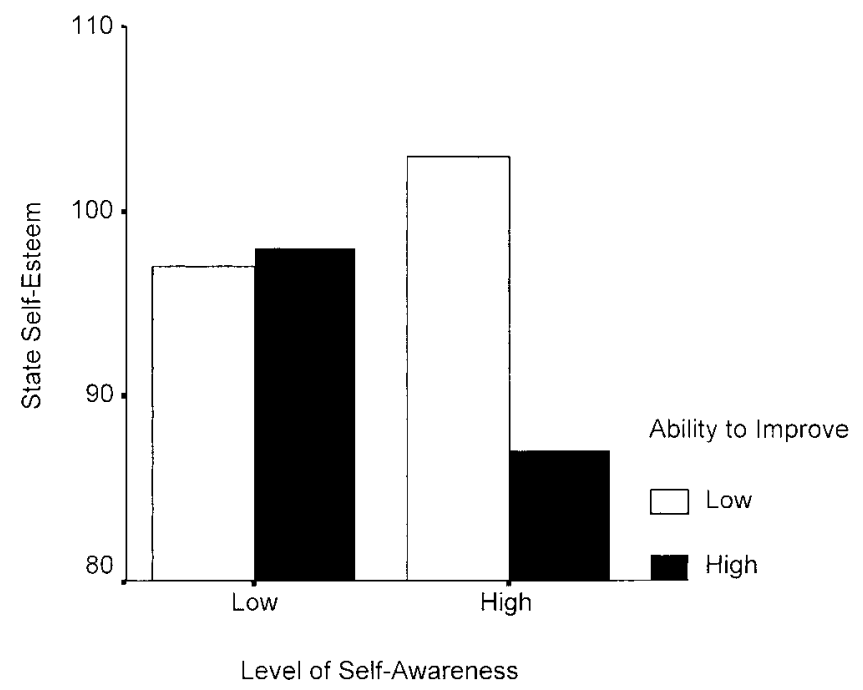

Figure 3. State self-esteem as a function of self-awareness and improvement likelihood: Study 2.

failure internally and experience reduced self-esteem is difficult to reconcile with views of the self-serving bias assuming that the self-esteem motive dominates attribution processes (Snyder et al., 1978) or the possibility that expecting improvement leads people to discount or brush off failure. Such findings are, however, fully consistent with our dual systems model.

We should note that this study also casts doubt on a possible criticism of Experiment 1. One might argue that the probability of improvement manipulation implied that failure was due to an unstable factor such as effort. Because Experiment 2 found internal failure attributions on Experiment 1's internal-external index as well as on measures of both ability and effort, we view this possibility as unlikely.

\section{Experiment 3}

The first two experiments have shown how self-awareness and probability of improvement interactively determine failure attributions. But our position also makes predictions about success attributions. As noted earlier, when self is a plausible cause for success, an internal attribution will simultaneously enable a positive self-evaluation and an accurate causal appraisal. Selfawareness should thus increase the tendency to attribute success internally to self. To test this prediction, we added conditions in which people were told they had achieved the experiment's standard.

\section{Method}

\section{Participants}

Participants were 120 male undergraduates who volunteered to participate for extra course credit. Participants were randomly assigned to condition in a 2 (camera/no camera) $\times 3$ (success/failure-can improve/ failure-can't improve) factorial design.

\section{Procedure}

The procedure was almost identical to Experiments 1 and 2. We led some participants to believe they were discrepant from the standard. In
Experiment 3, however, we added high and low self-awareness/success conditions. Participants in these groups learned they met the standard for making quantitative judgments in three dimensions. Experiment 3 also used the same probability of improvement manipulation; participants were told they had either a high or low probability of future improvement. No probability of improvement information, however, was given in the success conditions. Pretesting indicated that it confused participants about their actual level of performance.

\section{Dependent Measures}

Participants completed the state self-esteem measure used in Experiment 2 (McFarland \& Ross, 1982). Attributions for task performance were measured using two items, "To what extent was your performance on the test caused by factors associated with yourself?" and "To what extent was your performance on the test caused by factors associated with the external environment?" Each question was answered on a 7-point scale anchored by not at all and very much.

As a check on the probability of improvement manipulation, participants were asked to indicate "To what extent can you improve your performance on the task in the future?" on a 7-point scale anchored by not at all and very much. Finally, evaluations of task performance were measured with responses to "Please rate the level of your performance on the quantitative judgment in three dimensions task you just completed" on a similar 7-point scale.

\section{Results}

\section{Manipulation Checks}

Failure feedback. A 2 (camera/no camera) $\times 3$ (success/ failure-can improve/failure-can't improve) ANOVA conducted on responses to "Please rate the level of your performance on the quantitative judgment in three dimensions task you just completed" revealed a single main effect for type of feedback, $F(2$, $114)=104.07, p<.001$. Means are presented in Table 2. When self-awareness was high, people who succeeded rated their performance more positively than did people who failed and expected improvement, $t(114)=5.45, p<.001$, and people who failed and did not expect improvement, $t(114)=5.71, p<.001$. The same pattern was found when self-awareness was low. People who succeeded viewed their performance more positively than did people who failed and expected improvement, $t(114)=4.94, p<$ .001 , and people who failed and did not expect improvement,

Table 2

Perceived Quality of Task Performance: Experiment 3

\begin{tabular}{llll}
\hline & \multicolumn{3}{c}{ Performance feedback } \\
\cline { 2 - 4 } & & \multicolumn{2}{c}{ Failure: Improvement } \\
\cline { 3 - 4 } Variable & Success & Likely & Unlikely \\
\hline Camera & & & \\
$M$ & 6.00 & 1.80 & 1.60 \\
$S D$ & 2.25 & 2.52 & 2.30 \\
No camera & & & \\
$M$ & 5.70 & 1.90 & 2.30 \\
$S D$ & 2.36 & 2.44 & 2.73 \\
\hline
\end{tabular}

Note. $n=20$ per cell. Higher numbers indicate higher perceived quality of performance. 
$t(114)=4.42, p<.001$. These findings suggest that the successfailure manipulation was successful.

Probability of improvement manipulation. A $2 \times 3$ ANOVA conducted on the probability of improvement manipulation check revealed a sole main effect for probability of improvement, $F(2$, $114)=27.14, p<.001$. Means are presented in Table 3. No significant differences between persons who succeeded and persons who failed but could improve were found, regardless of the level of self-awareness. However, participants in both of these conditions perceived their chances of improving as significantly higher relative to persons who failed but could not improve. This pattern appeared in the high self-awareness (all $t \mathrm{~s}>4.8$ ) and low self-awareness (all $t \mathrm{~s}>5.5$ ) conditions. These findings suggest that the probability of improvement manipulation was successful. Why persons in the success conditions also perceived their probability of improvement as high is unclear, although it may reflect a mood-congruent judgment effect (Gendolla, 2000; Gendolla, Abele, \& Krüsken, 2001).

\section{Attributions for Performance}

A $2 \times 3$ ANOVA performed on attributions for task performance revealed a main effect for feedback type, $F(2,114)=$ $19.86, p<.001$, qualified by a significant interaction, $F(2,114)=$ $7.82, p<.01$. The pattern is displayed in Figure 4 .

Failure attributions. When self-awareness was high, people expecting improvement attributed more failure to self than did persons not expecting improvement, $t(114)=4.43, p<.001$. When probability of improvement was high, highly self-aware persons attributed more failure to self than did mildly self-aware persons, $t(114)=2.43, p<.025$. But when probability of improvement was low, highly self-aware persons attributed less failure to self than did mildly self-aware persons, $t(114)=2.61, p<$ .02. Probability of improvement had no effects when selfawareness was low $t<1$. The pattern of results in these four cells replicates the findings obtained in Experiments 1 and 2.

Success attributions. Highly self-aware people attributed more success to self than did mildly self-aware persons, $t(114)=2.01$, $p<.05$. This replicates past experiments that found that heightened self-awareness increases self-attribution of success (Federoff \& Harvey, 1976). When self-awareness was high, people who succeeded attributed more causality to self than did people who

Table 3

Perceived Probability of Improvement: Experiment 3

\begin{tabular}{llll}
\hline & \multicolumn{3}{c}{ Performance feedback } \\
\cline { 2 - 4 } & & \multicolumn{2}{c}{ Failure: Improvement } \\
\cline { 3 - 4 } Variable & Success & Likely & Unlikely \\
\hline Camera & & & \\
$M$ & 4.60 & 5.40 & 2.30 \\
$S D$ & 1.70 & 1.42 & 1.76 \\
No camera & & & \\
$M$ & 4.50 & 5.60 & 1.90 \\
$S D$ & 1.38 & 1.18 & 1.51 \\
\hline
\end{tabular}

Note. $n=20$ per cell. Higher numbers indicate higher perceived probability of improvement.

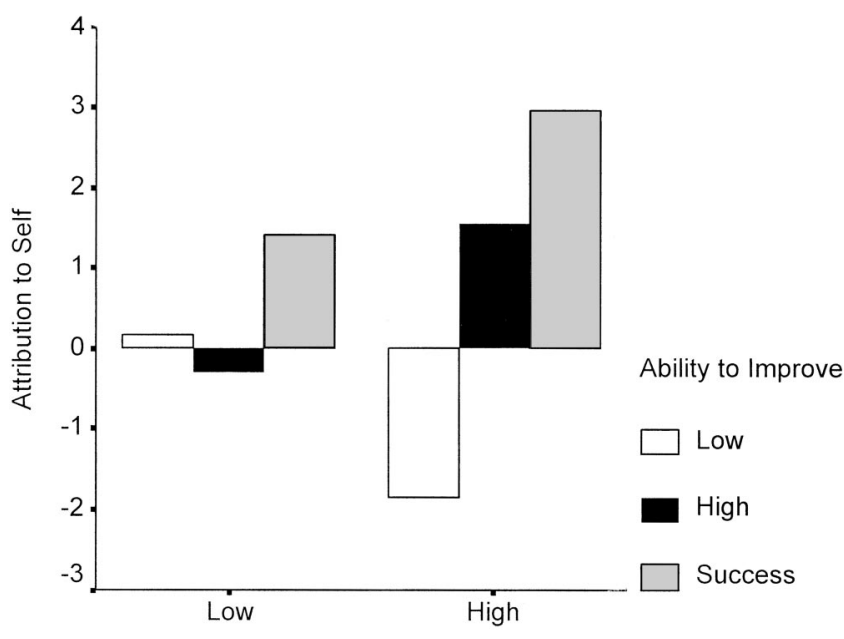

Level of Self-Awareness

Figure 4. Failure attribution to self as a function of self-awareness and success or failure feedback: Study 3.

failed but expected improvement, $t(114)=1.85, p<.05$ (onetailed), and people who failed but did not expect improvement, $t(114)=6.25, p<.001$. When self-awareness was low, the only difference found was significantly greater self-attribution by people who succeeded relative to people who failed and could improve, $t(114)=2.24, p<.01$.

\section{State Self-Esteem}

A $2 \times 3$ ANOVA performed on the state self-esteem scale revealed a significant main effect for the type of feedback, $F(2,114)=6.37$, $p<.02$, qualified by a significant interaction, $F(2,114)=7.71, p<$ .01 . The pattern is shown in Figure 5. When people succeeded, high self-awareness increased self-esteem, $t(114)=3.14, p<.005$. When

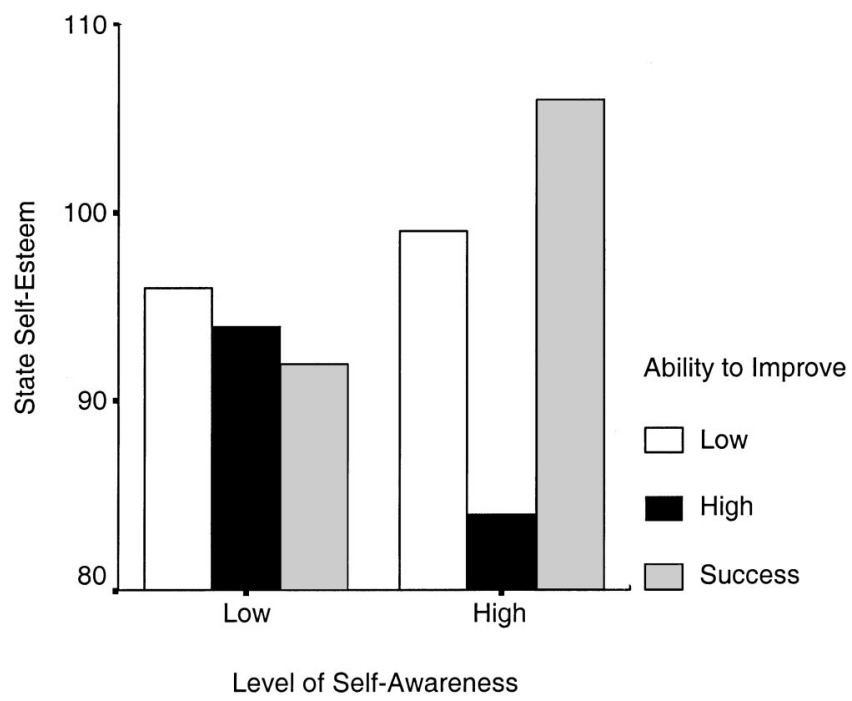

Figure 5. State self-esteen as a function of self-awareness and success or failure feedback: Study 3 . 
people failed but could improve, high self-awareness decreased selfesteem, $t(114)=2.41, p<.025$. Yet when people failed but could not improve, self-awareness had no effect on self-esteem, $t<1$.

When self-awareness was high, people who failed but expected improvement had lower self-esteem than did both people who failed but did not expect improvement, $t(114)=3.48, p<.001$, and people who succeeded, $t(114)=5.12, p<.001$. The success condition did not differ from the group that failed and did not expect improvement, $t(114)=1.63$, ns. No differences were found among the low self-awareness conditions, all $t \mathrm{~s}<1$.

\section{Mediational Analyses}

As in Experiment 2, we expected that the effects of probability of improvement on self-esteem were mediated by attributions for success and failure. The success and failure conditions were analyzed separately because no improvement information was given in the success conditions. Within the success conditions, attributions and self-esteem were significantly correlated. As expected, increased self-attribution of success was positively correlated with higher self-esteem $(r=.78, p<.001)$.

Within the failure conditions, we conducted a series of regression analyses to assess mediation indirectly (Baron \& Kenny, 1986) on the basis of the responses of persons in the high selfawareness conditions. Probability of improvement significantly predicted both self-esteem $(\beta=.629, p<.001)$ and failure attributions $(\beta=-.704, p<.001)$. Yet when probability of improvement and failure attributions were considered simultaneously, probability of improvement no longer predicted selfesteem significantly $(\beta=.08, n s)$. Attributions, however, did significantly predict self-esteem $(\beta=-.781, p<.001)$. This pattern suggests, as expected, that effects of improvement likelihood on self-esteem were due to attributions for failure.

To assess mediation directly, we conducted Baron and Kenny's (1986) modified version of the Sobel (1982) test (see Kenny et al., 1998, p. 260). This test also revealed that the effect of improvement likelihood on self-esteem was significantly mediated by failure attributions $(Z=4.32, p<.001)$.

\section{Discussion}

Experiment 3 tested our predictions for success attributions. As expected, increasing self-awareness increased the tendency to attribute success internally. Attributing success to self in turn increased self-esteem. Experiment 3 also replicated the first two experiments. As before, highly self-focused people attributed failure internally when their probability of improvement was high, and externally when their probability of improvement was low. These attributions had corresponding effects on state self-esteem, thus replicating Experiment 2. The manipulation check of perceived performance eliminated another possible criticism of this procedure. One might argue that improvement information influenced the perception of performance. Perhaps people who expected to improve did not perceive their failure as particularly severe. We view this as unlikely because the high and low probability of improvement conditions rated their performance equally negatively (see Table 2).

As noted earlier, Experiment 2 found a significant unmediated path between probability of improvement and state self-esteem.
Experiment 3, however, did not find a significant unmediated path; failure attributions fully mediated the effects of improvement beliefs on state self-esteem. We are inclined to place more confidence in Experiment 3's finding. Experiment 2's small sample size $(n=20)$ is not as large as one would like for multiple regression analyses (Cohen \& Cohen, 1983). Experiment 3, in contrast, had twice as many participants and thus more adequate power for testing mediational hypotheses. Nonetheless, it seems reasonable that additional, unmeasured mediators might be relevant. Our theory would expect, for instance, that a high probability of improvement might influence the importance of the discrepancy, which could also mediate its effects on state self-esteem. Either way, both experiments found that attributions significantly mediated the effects of improvement beliefs on state self-esteem; it remains for future research to identify other possible mediators.

We should note here that Experiment 3, as did the first two studies, involved only male participants. The composition of the participant pool at the time made it difficult to obtain equal numbers of men and women. We believe, though, that this does not constrain our interpretations very much. Although men and women surely differ in some of their internalized standards, self-awareness research has never found gender differences in the theory's basic processes and mechanisms (Duval \& Silvia, 2001). An extension of this work using almost all female participants also replicated the effects of self-awareness and improvement likelihood on failure attribution (Silvia \& Duval, 2001b).

\section{General Discussion}

Reviewers of the self-serving bias literature often note that the effect is inconsistent (Campbell \& Sedikides, 1999; Zuckerman, 1979). Although internal success attributions are consistently found (Miller \& Ross, 1975), internal and external failure attributions are both common findings in the empirical literature. The presence of inconsistent findings usually suggests that uncontrolled moderators are operating, and highlights the need for a new model capable of explaining the diverging results. We have proposed a model including two moderators, level of self-awareness and perceived probability of improvement, that might help resolve some of the empirical disparities.

Our model assumes that motives associated with two systems, a system comparing self against standards of correctness and a causal attribution system, jointly determine success and failure attributions. The SSCS prefers identity between self and standards (Duval \& Silvia, 2001; Duval \& Wicklund, 1972), whereas the attribution system prefers events to be attributed to a plausible cause (Heider, 1958). These motives are harmonious when self is a plausible cause for success. Attributing success to self would promote a positive self-evaluation, and the event would be connected with a plausible cause. An attribution of success to self should occur because it simultaneously furthers the goals of both systems. Experiment 3 supported this hypothesis. People who had met the performance standard made greater internal attributions than did persons who had failed; this effect was enhanced when self-focus was high.

But the systems' goals conflict when self is a plausible cause for failure. In this situation, we expected that the perceived probability of improving poor performance determines failure attributions; past research shows that improvement beliefs moderate many 
forms of self-enhancing activity (Dunning, 1995; Duval \& Duval, 1983, 1987; Hong et al., 1999). When highly self-focused people feel that failure can be rapidly remedied, they will attribute failure to self; when the likelihood of improvement seems low, however, failure will be attributed externally. All three experiments supported this hypothesis. Participants who believed they could improve their failing performance attributed more causality to self when self-focus was high. Conversely, self-focus enhanced the tendency to externalize failure when performance could not be improved.

Finally, Experiments 2 and 3 showed the consequences of success and failure attributions for self-esteem. Mediation analyses found that internal success attributions increased self-esteem and internal failure attributions decreased self-esteem. Nondefensiveness thus comes at a cost. Identifying times when people accept responsibility for failure and suffer a loss of self-esteem contradicts egotism models of causal attribution (Snyder et al., 1978; Zuckerman, 1979) and the notion that the self-enhancement motives dominates the self-assessment motive (Sedikides, 1993). But this should not be surprising-internal failure attributions and resulting self-esteem losses occur frequently in everyday life. Furthermore, as Heider (1958) argued, both self-evaluative and informational motives influence judgment and perception. If the self-assessment motive is independent from the self-evaluation motive, instead of subordinate to it (Sedikides, 1993), then there should be some conditions promoting accurate informational goals over self-enhancement goals.

\section{Reconsidering the Self-Serving Bias Literature}

How well does our model account for the self-serving bias literature? First, the present model predicts greater self-attribution for success; this prediction is compatible with reviews indicating that self-enhancing success attributions are consistently found (Miller \& Ross, 1975). In contrast, considerable variability exists with regard to failure attributions. Our model suggests several reasons why both internal and external failure attributions are found. Many studies have used procedures that were selfirrelevant. In a recent meta-analysis, Campbell and Sedikides (1999) demonstrated that increased self-threat amplifies the selfserving bias. When there was little self-threat, non-self-serving attributions were found. In the context of our model, minimal self-threat translates into circumstances having few implications for how self relates to important standards. Because the costs to the SSCS of an internal failure attribution are low, the attribution system will attribute failure to self.

A second reason why past studies have yielded contradictory findings for failure attributions involves the confounding of failure feedback with improvement feedback. Zuckerman (1979) concluded that the achievement paradigm, in which participants work on a task and receive success or failure feedback, is the only paradigm consistently finding external failure attributions. This paradigm is probably so effective because popular methods of inducing failure also engender a low likelihood of improvement. Most studies use novel tasks such as timed anagram unscrambling, Mednick's (1962) Remote Associates Task, or our own threedimensional mental rotation task, to make failure feedback plausible. Participants naturally do not expect ever to encounter and work on these esoteric tasks and will thus perceive a low proba- bility of future improvement. Other studies induce failure by giving false personality feedback. The personality traits that are used, such as social perceptiveness (e.g., Miller, 1976), are probably interpreted by the participant as being stable and unchangeable self-aspects. This will also reduce a person's perceived probability of improving.

Duval and Duval (1987) argued that studies finding internal failure attributions used procedures that, perhaps accidentally, produced the perception that failure could be improved. Weary et al. (1982), for example, asked participants to present a therapy outline to individuals having mild phobias; some participants were led to believe that their performance was a failure. Approximately one half of these persons were then asked to return in one week and re-administer the same therapy outline to their client; others were not led to believe they would have another opportunity. From our approach, people who expected to re-administer therapy would at least have the opportunity to potentially improve and thus perceived a reasonable probability of improving. As in the present studies, this promoted attributed failure to self. People who did not expect a second opportunity essentially felt unable to improve and, as predicted by our theory, attributed failure to external factors.

Ross et al.'s (1974) findings yield to a similar analysis. Experienced schoolteachers and undergraduates with no training in education were asked to teach an 11-year-old boy how to spell. One half of the participants were then told that the young boy had done poorly on a subsequent spelling task. The schoolteachers attributed causality for their failing performance to themselves, but the novice undergraduates attributed failure externally. The professional teachers certainly anticipated having future opportunities to improve their teaching skills and thus attributed failure to self. The untrained undergraduates, on the other hand, probably did not expect future improvement opportunities and thus did not expect future improvement.

\section{Relations to Other Perspectives}

\section{Perceived Probability of Improvement and Self-Efficacy}

Self-efficacy is the belief that one can enact a specific behavior or set of behaviors; outcome efficacy is the belief that certain behaviors exist that if enacted will be effective in reaching a desired goal (Bandura, 1977). Perceptions of the probability of improving incorporate both elements. Inasmuch as people believe they can improve, they should think that behaviors exist that if enacted would elevate performance, as well as that they can effectively carry out those actions. Inasmuch as people believe they cannot improve, they think that no means of reducing selfstandard discrepancies are available or that they have little capacity to act in ways thought to be efficacious. The effects of probability of improvement on attribution can be understood as reflecting the impact of particular combinations of self and outcome efficacy levels on causal attribution.

\section{Trait Malleability, Attribution, and Self-Esteem}

Earlier we briefly discussed how Dweck's research on selftheories intersects with our model of self-serving attribution. It is tempting to assume that incremental theorists generally feel able to improve after failure because their implicit theory of self views 
personal attributes as malleable (Dweck et al., 1995). Perceived probability of improvement then moderates attribution for failure. Consistent with this notion, incremental theorists assigned slightly more causal influence for failure to both ability and effort (a combined percentage of 57.7) than to task difficulty and luck (a combined percentage of 42.3; Hong et al., 1999). Pursuing this line of thought, entity theorists might be people doubting their capacity to improve because they construe traits as being relatively unchangeable. Believing that improvement is improbable then moderates their attributions for failure. Yet if entity theorists actually represent a low probability of improvement group, they fail to show any preference for external over internal attributions (a combined $48.3 \%$ for task difficulty + luck, and $51.7 \%$ for ability + effort). Entity theorists also tend to overattribute failure to ability (33.9\%) relative to effort (17.8\%), relative to our finding that manipulated expectancies led to equal attribution to ability and effort (Experiment 2).

Given this pattern, we are disinclined to argue that individual differences in the belief that personal attributes are changeable reflect cognitions that are psychologically equivalent to high and low probability of improvement beliefs. Indeed, to take this position would be tantamount to proposing that incremental and entity theorists are simply people who, for whatever reason, have differing estimates of self and outcome efficacy, an interpretation that flies in the face of ancillary evidence collected by Dweck and her colleagues (e.g., Dweck et al., 1995; Hong et al., 1999) suggesting that the differing self-theories reflect distinct and complex cognitive frameworks and goal orientations.

Nonetheless, our results can inform some of findings in the self-theories literature. The effects of internal failure attributions on self-esteem, for example, are consistent with the behavior of incremental and entity theorists. Incremental theorists should experience lower self-esteem after an internal failure attribution (Experiments 2 and 3). But because they attributed causality to personal attributes seen as malleable, they should also expect future improvement and restoration of self-esteem. In fact, Hong et al. (1999) found that incremental theorists are more interested in pursuing remedial activity following failure. When trait malleability is manipulated (Dunning, 1995), persons perceiving abilities to be malleable show interest in tasks on which they would presumably get positive feedback.

Entity theorists should also experience lowered self-esteem following attribution for failure to ability. Yet they should not expect improvement and state self-esteem restoration because they see the attribute as unchangeable. Both lowered self-esteem and perceiving events as uncontrollable are compatible with the suggestion that entity theorists sometimes show learned helplessness after failure (e.g., Dweck et al., 1995; Hong et al., 1999). In fact, entity theorists actively avoid remedial situations and show little interest in challenging tasks that might improve their abilities (Hong et al., 1999). Furthermore, when perceived trait malleability is manipulated (Dunning, 1995), people perceiving the ability as unmalleable avoid tasks for which performance feedback, and thus a possible reminder of personal failings, is likely. The relationship between attribution and self-esteem found in the present experiments is thus consistent with research on dispositional and manipulated beliefs about the malleability of traits (Dunning, 1995; Hong et al., 1999).

\section{Improvement Beliefs and Counterfactual Thought}

Counterfactual thought (Kahneman \& Tversky, 1982) is also relevant to our model, inasmuch as the perceived ability to change an event influences self-blame. People asked to imagine experiencing a negative outcome that could have been changed were more likely to say they would blame self and experience negative affect than were people who thought that a change in the negative outcome was unlikely (Boninger, Gleicher, \& Strathman, 1994). From our perspective, the "can change" versus "cannot change" conditions correspond to high and low probability of improvement manipulations. As would be expected from the dual systems approach, people who imagined a malleable outcome attributed more causality for the unpleasant event to self (assuming that self-blame represents attribution of causality to self) and reported experiencing higher levels of negative affect in the moment than did people who imagined an unchangeable outcome. This pattern of attribution and affect was obtained only for people who, because of either situational or dispositional factors, tended to focus on present rather than future behaviors. This result is also comprehensible from the dual systems perspective. On the basis of self-awareness theory (Duval \& Wicklund, 1972) and research on deindividuation (Diener, 1979), people focused on current activities were probably higher in self-focus than were people focused on the future. If high self-awareness is required for these effects, as our experiments suggest, then heightened self-blame and experienced negative affect would only be expected when people focused on current activities.

\section{Does Self-Awareness Always Moderate Success and Failure Attributions?}

The dual systems approach is based on the case in which the causal attribution system intersects with the SSCS. These systems can intersect only inasmuch as they are operating simultaneously. A lot of research shows that a person's level of self-focus determines the degree of self-standard comparison (Duval \& Silvia, 2001). When self-focus is low, people are not very concerned with meeting their standards (Silvia \& Gendolla, 2001). This position clearly suggests that self-focus moderates attribution for events that could potentially influence congruity between self and standards. Indeed, the present results and related research (Silvia \& Duval, 2001b) support this prediction. This suggests that participants in previous research showing a self-serving bias were relatively high in self-focus. Cases in which no self-serving biases are found, which are more numerous than might be expected (Campbell \& Sedikides, 1999; Zuckerman, 1979), could involve situations associated with low levels of self-awareness. Indeed, some of the circumstances that induce self-focus-self-reflection, being observed and evaluated, and social interaction (Duval \& Silvia, 2001) — are common elements in many social psychological experiments, so it is not unreasonable to suggest that self-awareness is an uncontrolled moderator in this literature. Further tests of this tentative conclusion await future research.

\section{Coping, Control, and Attribution}

Tennen, Affleck, and Gershman (1986) suggested that selfattribution for negative events-or more specifically, self- 
blame-increases self-efficacy. Increases in self-efficacy then enhance problem-focused coping. A path analysis found that mothers' self-blame for their children's perinatal complications appeared to mediate level of self-efficacy; self-efficacy then influenced behaviors classified as effective coping strategies. Our research strongly suggests that the causal relationship between selfefficacy and self-blame is in the opposite direction. Perceived capacity to improve, a variable that includes self-efficacy as a component, moderates self-attribution. Lalwani and Duval (2000), for example, found that perceiving resources to be sufficient to deal with a potential problem (high self-efficacy) increases selfattribution of responsibility for coping with the problem. Other research found that causal attribution, at least to effort, mediates interest in activities designed to remedy failure (Hong et al., 1999).

Taken together, this research suggests, on the one hand, that the causal path goes from perceived probability of improvement to causal attribution to coping behavior. On the other hand, although this pattern strikes us as more plausible, causality could be bidirectional. Self-blame for a negative outcome might represent an acceptance of personal responsibility for that event or situation. As Tennen et al. (1986) suggested, accepting responsibility could, in some sense, empower the individual and lead to efforts designed to manage the troubled person-environment interaction. Future research should try to clarify this issue.

\section{A Matter of Time}

The dynamics of the dual systems approach involve processes unfolding over time. To the extent that individuals believe they can improve failure, they will attribute causality to self. Although this results in lowered state self-esteem at Time 1, it also appears to result in action designed to ameliorate the negative situation (Hong et al., 1999). If this activity effectively resolves the problem, one would expect internal attributions for these successes. Given the results of Experiments 2 and 3 (cf. McFarland \& Ross, 1982), those attributions should eventually increase state self-esteem to previous levels, or perhaps even result in a net gain. These experiences might, in the long term, influence the development of enduring notions of self-efficacy (Bandura, 1977) or theories of trait malleability (Dweck et al., 1995). However, as is always the case with dynamical systems, tests of these projections require investigations including time as an independent variable.

\section{References}

Ames, R. (1975). Teachers' attributions of responsibility: Some unexpected nondefensive effects. Journal of Educational Psychology, 67, 668-676.

Bandura, A. (1977). Self-efficacy: Toward a unifying theory of behavioral change. Psychological Review, 84, 191-215.

Baron, R. M., \& Kenny, D. A. (1986). The moderator-mediator variable distinction in social psychological research: Conceptual, strategic, and statistical considerations. Journal of Personality and Social Psychology, 51, 1173-1182.

Boninger, D. S., Gleicher, F., \& Strathman, A. (1994). Counterfactual thinking: From what might have been to what may be. Journal of Personality and Social Psychology, 67, 297-307.

Brown, J. D., \& Rogers, R. J. (1991). Self-serving attributions: The role of physiological arousal. Personality and Social Psychology Bulletin, 17, 501-506.
Campbell, W. K., \& Sedikides, C. (1999). Self-threat magnifies the selfserving bias: A meta-analytic integration. Review of General Psychology, 3, 23-43.

Carver, C. S., \& Scheier, M. F. (1978). Self-focusing effects of dispositional self-consciousness, mirror presence, and audience presence. Journal of Personality and Social Psychology, 36, 324-332.

Carver, C. S., \& Scheier, M. F. (1998). On the self-regulation of behavior. New York: Cambridge University.

Cohen, J., \& Cohen, P. (1983). Applied multiple regression/correlation analysis for the behavioral sciences (2nd. ed). Hillsdale, NJ: Erlbaum.

Dana, E. R., Lalwani, N., \& Duval, T. S. (1997). Objective self-awareness and focus of attention following awareness of self-standard discrepancies: Changing self or changing standards of correctness. Journal of Social and Clinical Psychology, 16, 359-380.

Davis, D., \& Brock, T. C. (1975). Use of first-person pronouns as a function of increased objective self-awareness and performance feedback. Journal of Experimental Social Psychology, 11, 381-388.

Diener, E. (1979). Deindividuation, self-awareness, and disinhibition. Journal of Personality and Social Psychology, 37, 1160-1171.

Dunning, D. (1995). Trait importance and modifiability as factors influencing self-assessment and self-enhancement motives. Personality and Social Psychology Bulletin, 21, 1297-1306.

Dunning, D. (1999). A newer look: Motivated social cognition and the schematic representation of social concepts. Psychological Inquiry, 10, $1-11$.

Duval, T. S. (1976). Conformity on a visual task as a function of personal novelty on attitudinal dimensions and being reminded of object status of self. Journal of Experimental Social Psychology, 12, 87-98.

Duval, T. S., \& Duval, V. H. (1983). Consistency and cognition: A theory of causal attribution. Hillsdale, NJ: Erlbaum.

Duval, T. S., \& Duval, V. H. (1987). Level of perceived coping ability and attribution for negative events. Journal of Social and Clinical Psychology, 5, 452-468.

Duval, T. S., Duval, V. H., \& Mulilis, J. P. (1992). Effects of self-focus, discrepancy between self and standard, and outcome expectancy favorability on the tendency to match self to standard or withdraw. Journal of Personality and Social Psychology, 62, 340-348.

Duval, T. S., \& Lalwani, N. (1999). Objective self-awareness and causal attributions for self-standard discrepancies: Changing self or changing standards of correctness. Personality and Social Psychology Bulletin, 25, $1220-1229$.

Duval, T. S., \& Silvia, P. J. (2001). Self-awareness and causal attribution: A dual-systems theory. Boston: Kluwer Academic.

Duval, T. S., \& Wicklund, R. A. (1972). A theory of objective selfawareness. New York: Academic Press.

Dweck, C. S., Chiu, C., \& Hong, Y. (1995). Implicit theories and their role in judgments and reactions: A world from two perspectives, Psychology Inquiry, 6, 267-285.

Federoff, N. A., \& Harvey, J. A. (1976). Focus of attention, self-esteem and attribution of causality. Journal of Research in Personality, 10, 336345 .

Festinger, L. (1954). A theory of social comparison processes. Human Relations, 7, 117-140.

Gendolla, G. H. E. (2000). On the impact of mood on behavior: An integrative theory and a review. Review of General Psychology, 4, $378-408$.

Gendolla, G. H. E., Abele, A. E., \& Krüsken, J. (2001). The informational impact of mood on effort mobilization: A study of cardiovascular and electrodermal responses. Emotion, 1, 12-24.

Heatherton, T. F., \& Polivy, J. (1991). Development and validation of a scale for measuring state self-esteem. Journal of Personality and Social Psychology, 60, 895-910.

Heider, F. (1944). Social perception and phenomenal causality. Psychological Review, 51, 358-374. 
Heider, F. (1958). The psychology of interpersonal relations. New York: Wiley.

Hong, Y., Chiu, C., Dweck, C. S., Lin, D. M. S., \& Wan, W. (1999). Implicit theories, attributions, and coping: A meaning system approach. Journal of Personality and Social Psychology, 77, 588-599.

Ickes, W. J., Wicklund, R. A., \& Ferris, C. B. (1973). Objective self awareness and self-esteem. Journal of Experimental Social Psychology, 9, 202-219.

Kahneman, D., \& Tversky, A. (1982). The simulation heuristic. In D. Kahneman, P. Slovic, \& A. Tversky (Eds.), Judgment under uncertainty (pp. 201-208). New York: Cambridge University.

Kenny, D. A., Kashy, D. A., \& Bolger, N. (1998). Data analysis in social psychology. In D. T. Gilbert, S. T. Fiske, \& G. Lindzey (Eds.), The handbook of social psychology (4th ed., Vol. 1, pp. 233-265). Boston: McGraw-Hill.

Lalwani, N., \& Duval, T. S. (2000). The moderating effects of cognitive appraisal processes on self-attribution of responsibility. Journal of Applied Social Psychology, 30, 2233-2245.

Lewin, K. (1935). A dynamic theory of personality. New York: McGrawHill.

McDonald, P. J. (1980). Reactions to objective self-awareness. Journal of Research in Personality, 14, 250-260.

McFarland, C., \& Ross, M. (1982). Impact of causal attributions on affective reactions to success and failure. Journal of Personality and Social Psychology, 43, 937-946.

Mednick, S. A. (1962). The associative basis of the creative process. Psychological Review, 26, 220-232.

Miller, D. T. (1976). Ego involvement and attributions for success and failure. Journal of Personality and Social Psychology, 34, 901-906.

Miller, D. T., \& Ross, M. (1975). Self-serving biases in the attribution of causality: Fact or fiction? Psychological Bulletin, 82, 213-225.

Nisbett, R., \& Ross, L. (1980). Human inference: Strategies and shortcomings of social judgment. Englewood Cliffs, NJ: Prentice-Hall.

Pedhazur, E. J. (1982). Multiple regression in behavioral research (2nd ed.). New York: Holt, Rinehart, \& Winston.

Ross, L., Bierbrauer, G., \& Polly, S. (1974). Attribution of educational outcomes by professional and nonprofessional instructors. Journal of Personality and Social Psychology, 29, 609-618.

Scheier, M. F., \& Carver, C. S. (1983). Self-directed attention and the comparison of self with standards. Journal of Experimental Social Psychology, 19, 205-222.

Scheier, M. F., Fenigstein, A., \& Buss, A. H. (1974). Self-awareness and physical aggression. Journal of Experimental Social Psychology, 10, 264-273.

Sedikides, C. (1992). Attentional effects on mood are moderated by chronic self-conception valence. Personality and Social Psychology Bulletin, 18, 580-584.

Sedikides, C. (1993). Assessment, enhancement, and verification determinants of the self-evaluation process. Journal of Personality and Social Psychology, 65, 317-338.

Sedikides, C., \& Strube, M. J. (1997). Self-evaluation: To thine own self be good, to thine own self be sure, to thine own self be true, and to thine own self be better. Advances in Experimental Social Psychology, 29, 206-269.

Silvia, P. J., \& Duval, T. S. (2001a). Objective self-awareness theory: Recent progress and enduring problems. Personality and Social Psychology Review, 5, 230-241.

Silvia, P. J., \& Duval, T. S. (2001b). Predicting the interpersonal targets of self-serving attributions. Journal of Experimental Social Psychology, 37, 333-340.

Silvia, P. J., \& Gendolla, G. H. E. (2001). On introspection and selfperception: Does self-focused attention enable accurate self-knowledge? Review of General Psychology, 5, 241-269.

Snyder, M. L., Stephan, W. G., \& Rosenfield, D. (1976). Egotism and attribution. Journal of Personality and Social Psychology, 33, 435-441.

Snyder, M. L., Stephan, W. G., \& Rosenfield, D. (1978). Attributional egotism. In J. H. Harvey, W. J. Ickes, \& R. F. Kidd (Eds.), New directions in attribution research (Vol. 2, pp. 91-117). Hillsdale, NJ: Erlbaum.

Sobel, M. E. (1982). Asymptotic intervals for indirect effects in structural equation models. In S. Leinhart (Ed.), Sociological methodology 1982 (pp. 290-312). San Francisco: Jossey-Bass.

Taylor, S. E., \& Brown, J. D. (1988). Illusion and well-being: A social psychological perspective on mental health. Psychological Bulletin, 103, 193-210.

Tennen, H., Affleck, G., \& Gershman, K. (1986). Self-blame among parents of infants with perinatal complications: The role of selfprotective motives. Journal of Personality and Social Psychology, 50, 690-696.

Treisman, A. M., \& Gelade, G. (1980). A feature-integration theory of attention. Cognitive Psychology, 12, 97-136.

Trope, Y. (1986). Self-enhancement and self-assessment in achievement behavior. In R. M. Sorrentino \& E. T. Higgins (Eds.), Handbook of motivation and cognition (Vol. 1, pp. 350-378). New York: Guilford.

Trope, Y., \& Neter, E. (1994). Reconciling competing motives in selfevaluation: The role of self-control in feedback seeking. Journal of Personality and Social Psychology, 66, 646-657.

Trope, Y., \& Pomerantz, E. M. (1998). Resolving conflicts among selfevaluative motives: Positive experiences as a resource for overcoming defensiveness. Motivation and Emotion, 22, 53-72.

Weary, G., Harvey, J. H., Schweiger, P., Olson, C. T., Perloff, R., \& Pritchard, S. (1982). Self-presentation and the moderation of self-serving attributional biases. Social Cognition, 1, 140-159.

Wong, P. T. P., \& Weiner, B. (1981). When people ask "why" questions and the heuristics of attributional search. Journal of Personality and Social Psychology, 41, 650-663.

Zuckerman, M. (1979). Attributions of success and failure revisited, or: The motivational bias is alive and well in attribution theory. Journal of Personality, 47, 245-287.
Received May 19, 2000

Revision received May 1, 2001

Accepted May 1, 2001 